\title{
18. ve 19. Asırda Fransızca Hazırlanmış Transkripsiyon Anıtlarında Okuma Metinlerinin Özellikleri
}

Yakup YILMAZ1

\begin{abstract}
$\ddot{\mathbf{O} z}$
18. ve 19. asırlarda, yabancı dil olarak Türkçenin öğretiminde hazırlanan kitaplara bakıldığında, Türklerin yazdıkları eserler yerine, ağırlıklı olarak medeniyet, diplomasi ve ticaret dili olan Fransızca ile kaleme alınmış eserler çıkar. Bu eserlerde ağırlıklı olarak gramer kuralları bulunur. Kelime merkezli bir anlatım söz konusudur. Bazılarında okuma metinleri verilmiştir. Bu metinleri eserdeki yerine, yapısına ve içeriğine göre incelemek gerekir. Eserlerin çoğunda müstakil metinden ziyade cümleler ve diyaloglar verilmiş; pek azında okuma metinleri sunulmuştur. Okuma metinleri incelenirken, metinler yapı, içerik ve tür olarak ana bölümü oluşturur; yapı içinde cümle ve metin alt bölümü, içerik içinde dini ve dünyevi konular alt bölümü, tür içinde diyalog, atasözü, fabl-fikra, manzum, mensur türler alt bölümü belirlenmiştir. Bunlar tasnif edildikten sonra metin kapsamında fabllar-fikralar, manzum metinler ve mensur metinler içerikleri bakımından değerlendirilmiştir. Sonuç olarak transkripsiyon anıtlarındaki okuma metinlerinde özellikle resmi yazışma öğretiminin öncelendiği, iki tanesinde akademik özellikli okuma öğretimi bulunduğu, okuma metni başlğ̆ altında bazılarında ileri düzeyde metinler bazllarında ise kolay metinler sunulduğu görülmüştür.
\end{abstract}

Anahtar kelimeler: Transkripsiyon anıtları-metinleri, okuma metni, yabancılar için Türkçe öğretimi.

\section{Characteristics of Reading Texts in 18th and 19th Century French Prepared Transcription Monuments}

\begin{abstract}
In the $18^{\text {th }}$ and $19^{\text {th }}$ centuries, when the books prepared in the teaching of Turkic languages as a foreign language are looked at, the works written by the Turks are replaced with works written in French which are mainly civilization, diplomacy and trade languages. These works mainly contain grammatical rules. It is a word-centric expression. Some have been given reading texts. It is necessary to examine these texts according to structure and content instead of the work. Quite a number of dialogues and dialogues were given from the independent text in most of the works; very few readings are available. While reading texts are examined, texts form the main part as structure, content and genre; sub-sections of sentences and texts in the structure, sub-sections of religious and secular topics in the context, dialogue in the genre, proverbs, fables, verses, verse and subspecies. After they were classified, the fables-fikralar, verse texts and texts were evaluated in terms of their contents. As a result, in reading texts in transcription monuments, it is seen that the official correspondence education is predominant, two of them have academic reading education, and some texts are advanced texts and others are easy texts.
\end{abstract}

Key words: Transcription monuments-texts, reading texts, teaching Turkish for foreigners.

Doç. Dr., Kırklareli Üniversitesi, Fen Edebiyat Fakültesi, Türk Dili ve Edebiyatı Bölümü, yilmazyakupbey@gmail.com [Makale kayit tarihi: 4.7.2018-kabul tarihi: 15.8.2018] 


\section{Giriş}

\section{Transkripsiyon metni nedir}

Türkçenin sözlük, gramer ve çeşitli metinlerinin Arap alfabesi dışında soldan sağa yazılan ve sese karşılık harf düzeninde yazılan alfabelerle yazılmış metinlerine Transkripsiyon metinleri denir.

İlk yazllan transkripsiyon metni olarak Codex Cumanicus olarak bilinir. Bu eserin yazımından Türklerin Arap alfabesini bırakmasına kadar olan devrede yabancıların yazdıkları eserlere transkripsiyon metinleri nazarıyla bakılır.

İstanbul'un fethine kadar transkripsiyon metinleri yazılmış olsa da çok seyrektir. İstanbul'un fethi Türklere olan ilgiyi, Türklerden korkuyu, Türkleri tanıma arzusunu ve Türklerle ilişki kurma ihtiyacını artırmış, bu ihtiyacı karşılamak için de çeşitli teşebbüslere girişilmiştir.

Türklerin Asya ve Avrupa'da zirvede olduğu zamanlarda artış gösteren bu eserlerin yazılma sebepleri arasında bu eserlerin önsözlerinde belirtildiği üzere

1. Türk devletleriyle irtibata geçmek isteyen Avrupa devletlerinin tercümanlarını yetiştirmek,

2. Türk devletleriyle ticari faaliyet içinde bulunan Avrupalı tüccarlara yardımcı olabilmek,

3. Türk halklarının arasında Hristiyanlığı yayması için yetiştirilen misyonerlere Türkçeyi kısa zamanda ve kolayca öğretmek,

4. Türk devletleriyle askeri, siyasi ve diplomatik ilişkileri kolaylaştırmak,

5. Türk devletleriyle irtibata geçmek için kullandıkları Hristiyan ve Musevi tercümanların hilelerinden, aldatmalarından kurtulmak,

6. Rusya gibi kendi sınırları dâhilindeki Türk halklarıyla irtibatları kolaylaştırmak ve sağlamlaştırmak,

7. Tamamen ilmi kaygılarla Türkçeyi ve Türk kültürünü tanımak yer almaktadır.

Transkripsiyon eserleri Latince, İtalyanca, Fransızca, Almanca, İngilizce, Lehçe, Rusça gibi çeşitli Batı dillerinde yazılmış olarak görülür. Bunlardan Fransızca sayı bakımından biraz daha öne çıkar. Bunun da sebebi başka dillere mensup devlet ve kişilerin de bu eserleri Fransızca yazmalarıdır. 18. ve 19. asırlarda Fransızca münevverlerin ve itibarlı kişilerin kullanmayı tercih ettiği bir dildir.

Transkripsiyon metinlerinin yazılma sıklı̆̆ı Türklerin Avrupa devletleriyle ilişkilerinin geliştĭği 18. ve 19. asırda artmış görünmektedir.

\section{Fransızca yazılmış Transkripsiyon metinleri}

18. ve 19. asırlarda yazılmış Transkripsiyon metinlerinden kaynaklarda tespit edilebilenleri şunlardır: 1730 İstanbul, J. B. Holdermann: Grammaire Turque 1789 Berlin, Joseph v. Preindl: Vocabulaire de la langue turque: 
1790 İstanbul, Pierre François Viguer: Elemens De La Langue Turque

1823 Paris, Amedee Jaubert: Elements de la Grammaire Turque:

1829 Budapeşte, J. K. Besse: Abrege de la Grammaire Turque et un Petit Vocabulaire en Français, Turc en Hongrois

1831 Paris, T. X. Bianchi: Vocabulaire Français-Turc

1831 Viyana, Artin Hindoglu: Dictionnaire abrégé turc-français

1833 Paris, Amedee Jaubert: Elements de la Grammaire Turque

1834 Paris, Artin Hindoglou: Grammaire Theorique et Pratique de la Langue Turke

1835-37 Paris, J. D. Kieffer; T. X. Bianchi: Dictionnaire Turc-Français

1835 Leipsic, Guillaume Schroeder: Grammaire Turque

1836 Paris, Arthur Lumley Davids: Grammaire Turke

1838 Paris, V Letellier: Vocabulaire Oriental, Français-Italien, Arabe, Turc et Grec

1838 Viyana, Artin Hindoğlu: Dictionnaire abrégé turc-français

1839 Paris, T.X. Bianchi: Le Guide de la Conversation en Français et en Turc

1840-41 Moskova, Prince Alexandre Handjeri: Dictionnaire français-arabe-persan et turc

1844 Venedik, Minas Medigi: Grammaire polyglotte contenant les princ

1846 Paris, Sir James Redhouse: Grammaire Raisonnee de la language Ottomane

1847 Viyana, Auguste Pfizmaier: Grammaire Turque

1850 Paris, J. D. Kieffer, T. X. Bianchi: Dictionnaire Turc-Français-1.C.

1852 Paris, T. X. Bianchi: Guide de la coversation en France et en Turc

1853 Leipzig, Ludwig Albert: Turkisch Grammatik

1854 Paris, Benjamin Duprat: Le Drogman Turc donnant les mots et les phrases

1854 Berlin, Fr. Dietrici: Chrestomathe Ottomane preceder de tableaux et suiver d'un glossaire turcfrançais

1854 Paris, Alexandre Timoni: Guide de la conversation Français-Turc

1855 Viyana, P. Samuel Catergian: Guide de conversation turc-français-allemand

1856 Paris, Charles Viotte: Grammaire turque courte et facile

1856 Paris, Luis Dubeux: Elements de la Gramaire Turque

1856 Paris, N. Mallouf: Dictionnaire Française-Turc

1861 Paris, Clement Huart: Grammaire Elementaire de la Langue Turque

1862 Paris, Nassif Mallouf: Grammaire Elementaire de la Langue Turque

1868 Constantinople, Mehmet Atuf: Dictionnaire Français, Turc et Italien

1870 Constantinople, Nedjib: Grammaire Elementaire de la Langue Turque

1873 Constantinople, Louis Charrel: Etudes Philologique sur la Langue Turque

1881 Paris, A. C. Barbier de Meynard: Dictionnaire turc-français 1

1883 Constantinople, Ch. Samy-Bey Fraschery: Kamus-ı Firansavi-Dictionnaire turc-français

1885-1888 İstanbul, Medico M. Dal: Methode Theorique et Pratique Pour L'enseignements de la Langue Turque

1886 Paris, A. C. Barbier de Meynard: Dictionnaire turc-français 2 
1888 Constantinople, R. Youssouf: 1-2-Dictionnaire turc-français en caractères latins

1891 Constantinople, B. Tinghir/ K. Sinapian: Dictionnaire français-turc des termes techniques des sciences, des lettres et des arts

1892 İstanbul, Jozeph Reali Youssouf: Grammaire Complete de la Langue Ottomane

$\mathrm{Bu}$ eserlerden dil bilgisi anlatımının yanında okuma metni içerenleri metinlerin yapısı, içeriği ve türü yönüyle değerlendirildi.

\section{Devrin yabancı dil öğretim yönteminde okumanın yeri}

Devrin yabancı dil öğretim yöntemine ve bu yöntemin okumaya bakışına da temas etmek gerekir. 18. ve 19. asırlarda revaçta olan yabancı dil öğretim yöntemi dil bilgisi-çeviri yöntemidir. Bu yöntemde okuma dört temel dil becerisinde ilk öğrenilmesi gereken beceridir. Yazılan ders kitapları dil bilgisi kurallarının ayrıntılı olarak anlatımını, kelime listelerini ve seçkin okuma metinlerini içermekte, bu metinler sesli okunup öğrencinin ana diline çevrilmektedir. Okuma metinlerine bakıldığında çoklukla klasik metinler veya edebi metinler üzerinden olmaktadır. Dört temel dil becerisinden okumanın yanında yazma becerisi de yer alır. Konuşmaya yarayacak malzeme olarak sadece diyaloglardan söz edilebilir.

Metinlerde okuma metinleri dışında konuşma alanına yönelik hazırlanmış atasözleri, vecizeler, diyaloglar yer alsa da bunlar okuma metni olarak görülmedi.

\section{Okuma metni bulunan Transkripsiyon metinleri}

1789 Berlin, Joseph v. Preindl: Vocabulaire de la langue turque: 163-171. s. 6 adet fabl; 172. s. 1 dua metni mevcut.

1823 Paris, Amedee Jaubert: Elements de la Grammaire Turque: İḥtirāk-ı Donanma ve 'Azl-i Kapudan Paşa (5 sayfalık nesih Arap harfli Türkçe metin); PL. 4-5 Buyruldu (Arap harfli nesih metin); PL. 6 Ferman (Arap harfli nesih metin); PL. 7-8 Tezkere-yi Evliyâ (Uygur harfli, satır altı Arap harfli metin); PL. 9 Transcription Turke (Arap harfli metin); PL. 10 Mi'râc (Uygur harfli metin); PL. 11 Transcription Turke (Arap harfli metin).

1829 Budapeşte, J. K. Besse: Abrege de la Grammaire Turque et un Petit Vocabulaire en Français, Turc en Hongrois: 5. s. Türkçe şarkı (-arar ve -zor redifli gazel).

1836 Paris, Arthur Lumley Davids (Çev.): Grammaire Turke: I. Uygur: 177-18o. s. Bahtiyar-nâme (Arap harfli metin); 184 s. Kutadgu Bilig (Arap harfli metin); 188. s. Kutadgu Bilig (Uygur harfli metin); 186. s. Mirâc (Arap harfli metin); 187. s. Mirâc ve Tezkire-yi Evliyâ (Uygur harfli metin); Tezkire-yi Evliyâ (Arfap harfli metin); II. Çağatay: 188-191. s. Bâbur-nâme (Arap harfli metin); 195-196. s. Kitâb1 Şecere-yi Türki (Arap harfli metin); 197. s. Mecâlisü’n-Nefâ’is (Arap harfli metin); III. Kıpçak: 198199. s. Ahvâl-i Cingiz Han ve Aksak Timur (Arap harfli metin); IV. Osmanlı: 201. s. Baki'nin 'édelim' gazeli; 202. s. Mesîhî’nin Bahar kasidesi (Arap harfli); 203-205. s. Evliya Çelebi Seyahat-nâmesi (Arap harfli metin); 206-207. s. Tuhfetü'l-Kibâr’ (Arap harfli metin); 208. s. Na'îmâ Tarihi (Arap harfli metin); 210. s. Acâyibü'l-Mahlûkât'tan (Arap harfli metin); 212-213. s. Humâyûn-nâme'den (Arap harfli metin).

1846 Paris, Sir James Redhouse: Grammaire Raisonnee de la language Ottomane: 277. s. Sultan 3. Selim'in Atlas Önsözü (Arap harfli metin) ve devamında bu metnin analizi mevcuttur. 
1852 Paris, T. X. Bianchi: Guide de la coversation en France et en Turc: Konuşma ve okuma öğretimi amaçlı hazırlanmış eser üç bölümden oluşur. İlk iki bölüm sözcük ve cümle öğretimi üzerindedir. Üçüncü bölümde ise tarihten coğrafyaya, edebiyattan siyasete hemen her konuda genişçe konuşma ve okuma metinleri mevcut.

1854 Berlin, Fr. Dietrici: Chrestomathe Ottomane preceder de tableaux et suiver d'un glossaire turcfrançais: Metinler tarafında 1-18. s. Der-liyâkat-i merhûm Mahmûd Paşa tâbe serâhu (Arap harfli metin); 19-31. s. Hikâyât Mecmûası (15 adet Arap harfli hikaye); 31-38. s. Hoca Nasreddin Merhûmun Ba'z Hikâyâtı (7 adet Arap harfli hikaye); 38-43. s. Risâle-yi Birgivî'den Me'hûz Birkaç Fasl (Arap harfli metin); 43-46. s. Bir Va’z-ı Nasrânînnin Evvel Kelâmı (Arap harfli metin); 47-55. s. Cihân-nümâ'dan Birkaç Mâdde (Arap harfli metin); 55-59. s. Lehçetü'l-Lügat'tan Birkaç Mâdde (Arap harfli metin); 596o. s. Takvîm-i Vakâyi”den (Arap harfli metin).

1856 Paris, Charles Viotte: Grammaire turque courte et facile: Mektuplar, Fabllar, Flkralar ve Atasözleri başlığı altında 260-263. s. 3 adet mektup (Latin harfli metin); 264-268. s. 3 adet fabl (Latin harfli metin); 268-270. s. 6 adet anekdot yani Nasreddin Hoca fikrası (Latin harfli metin); 272-276. s. 45 atasözü (Latin harfli metin) mevcuttur.

1861 (son baskısı 24 Aralık 1876 sonrası) Paris, N. Mallouf (Clement Huart incelemsi ve düzeltmesiyle): Grammaire Elementaire de la Langue Turque: 149-176. s. Mecmû'a-yı Tahrîrât başlı̆̆ı altında aslında yazma alıştırmaları tarzında 29 adet günlük ve 1 adet Encümen-i Daniş’in kuruluş fermanı mevcuttur; ancak bunlar okuma metni niteliğini de taşımaktadır (Arap harfli metin). 177-19o. s. Hatt Imperial (Hatt-ı Humâyûn) başlığı altında fermanlar yer alır (Arap harfli metin). İlki I. Abdülaziz Han'ın, ikincisi II. Abdülhamid Han'ın, üçüncüsü Kanun-ı Esasi'nin ilan fermanıdır (Arap harfli metin). 1862 baskısında eklenen metinler: 160-167. s. Osmanlı Devleti ile Fransa arasındaki ticaret anlaşmasının genişletilmesi (Arap harfli metin); 190-202. s. Osmanlı Devleti ile Fransa arasındaki ticaret anlaşmasının genişletilmesi metinleri yer alır (Arap harfli metin).

\section{Değerlendirme}

Metinler incelendiğinde şu sonuçları elde etmek mümkündür:

1789 Berlin, Preindl: 6 adet fabl ve bir dua metni ile basitçe sayllabilecek okuma metinler sunmuştur. Dua metni de Hristiyani bir dua metnidir.

1823 Paris, Jaubert: Sunulan metinlerden hareketle amacın resmi yazışmayı öğretmek olduğu düşünülebilir. Ayrıca Uygur harfli metinler sunması Türkolojiye dönük çalışmalarının olduğunu da düşündürür.

1829 Budapeşte, Besse: Bir şarkı sunmak metin sunmak olmadığından okuma metni var denemez.

1836 Paris, Arthur Lumley Davids: Sunduğu metinleri Uygur, Çağatay, Kipçak, Osmanlı şeklinde tasnif etmesinden dolayı bu eserin amacının Türkçeyi öğretmek değil Türkolojiye giriş yapmak olduğu anlaşlır.

1846 Paris, Redhouse: 3. Selim’in Atlas Önsözünün sunulması ve incelenmesi okuma metni sayılamaz. 
1852 Paris, T. X. Bianchi: Bu eser okuma metinleri yönüyle bu asırdaki en zengin eserdir. Her konuda metin sunulmuştur. Ayrıca resmi yazışma örnekleri de verilmiştir.

1854 Berlin, Fr. Dietrici: Türkçe metinlerden örnekler sunulmuş, hikayeler, Birgivi'den ve cihannüma'dan örnek metinler verilmiştir.

1856 Paris, Charles Viotte: Mektuplar, fabllar, fikralar ve atasözleri sunulmuştur. Diğerlerinden farklı olarak okuma metinleri bu eserde özellikle Latin harfli verilmiştir.

1861 (son baskısı 24 Aralık 1876 sonrası) Paris, N. Mallouf (Clement Huart incelemsi ve düzeltmesiyle): Yazma örneği olsun diye günlük tarzında metinler sunulmuş, bunlar aynı zamanda okuma metni niteliğindedir. Ayrıca burada okumadan ziyade yazma öğretimine öncelik ve önem verildiği görülür.

\section{Sonuç}

18. ve 19. asırda Fransızca yazılmış transkripsiyon metinleri sözlüklerde bulunmamaktadır. Özellikle gramer kitaplarında ve müstakilen de konuşma kitaplarında yer alır. Bu metinlerde kullanılan alfabe 1 tanesi hariç Arap harfleriyle, 1 tanesi ise Latin harfleriyle oluşturulmuştur.

Okuma metinlerinde özellikle resmi yazışma öğretimi öncelenmiştir. İki tanesinde akademik özellikli okuma öğretimi görülmektedir. Okuma metni deyince bazllarında ileri düzeyde metinler görülürken, bazılarında ise kolay metinler seçilmiştir. Bu da eserin hedef kitlesine göre değişmektedir.

Buraya almadığımız özellikle diyalog tarzındaki metinler okuma metni olmayıp daha çok konuşma içerik ve nitelikli metin niteliğindedir.

\section{Kaynakça}

Albert, L. (1853). Turkisch Grammatik . Leipzig.

Atuf, M. (1868). Dictionnaire Français, Turc et Italien. Constantinople.

Barbier de Meynard, A. C. (1881). Dictionnaire turc-français 1. Paris.

Barbier de Meynard, A. C. (1886). Dictionnaire turc-français 2. Paris.

Besse, J. K. (1829). Abrege de la Grammaire Turque et un Petit Vocabulaire en Français, Turc en Hongrois. Budapeşte.

Bianchi, T. (1839). Le Guide de la Conversation en Français et en Turc. Paris.

Bianchi, T. X. (1831). Vocabulaire Français-Turc. Paris.

Bianchi, T. X. (1852). Guide de la coversation en France et en Turc. Paris.

Catergian, P. S. (1855). Guide de conversation turc-français-allemand . Viyana.

Charrel, L. (1873). Etudes Philologique sur la Langue Turque. Constantinople.

Dal, M. M. (1885). Methode Theorique et Pratique Pour L'enseignements de la Langue Turque. İstanbul.

Davids, A. L. (1836). Grammaire Turke. Paris.

Dietrici, F. (1854). Chrestomathe Ottomane preceder de tableaux et suiver d'un glossaire turc-français. Berlin.

Dubeux, L. (1856). Elements de la Gramaire Turque. Paris. 
Duprat, B. (1854). Le Drogman Turc donnant les mots et les phrases. Paris.

Fraschery, S.-B. (1883). Kamus-ı Firansavi-Dictionnaire turc-français. Constantinople.

Handjeri, P. A. (1840). Dictionnaire français-arabe-persan et turc. Moskova.

Hindoglou, A. (1834). Grammaire Theorique et Pratique de la Langue Turke. Paris.

Hindoglu, A. (1831). Dictionnaire abrégé turc-français. Viyana.

Hindoğlu, A. (1838). Dictionnaire abrégé turc-français . Viyana.

Holdermann, J. B. (1730). Grammaire Turque Ou Methode Courte Et Facile Pour Apprendre La Langue Turque. İstanbul: Dâr-ı Tıbâa-yı Âmire.

Huart, C. (1861). Grammaire Elementaire de la Langue Turque . Paris.

Jaubert, A. (1823). Elements de la Grammaire Turque. Paris.

Jaubert, A. (1833). Elements de la Grammaire Turque. Paris.

Kieffer, J. D., \& Bianchi, T. X. (1835). Dictionnaire Turc-Français. Paris.

Kieffer, J. D., \& Bianchi, T. X. (1850). Dictionnaire Turc-Français. Paris.

Letellier, V. (1838 ). Vocabulaire Oriental, Français-Italien, Arabe, Turc et Grec. Paris.

Mallouf, N. (1856). Dictionnaire Française-Turc. Paris.

Mallouf, N. (1862). Grammaire Elementaire de la Langue Turque . Paris.

Medigi, M. (1844). Grammaire polyglotte contenant les princ. Venedik.

Nedjib. (1870). Grammaire Elementaire de la Langue Turque. Constantinople.

Pfizmaier, A. (1847). Grammaire Turque. Viyana.

Preindl, J. v. (1789). Vocabulaire de la langue turque: . Berlin.

Redhouse, S. J. (1846). Grammaire Raisonnee de la language Ottomane. Paris.

Schroeder, G. (1835). Grammaire Turque. Leipsic.

Timoni, A. (1854). Guide de la conversation Français-Turc. Paris.

Tinghir, B., \& Sinapian, K. (1891). Dictionnaire français-turc des termes techniques des sciences, des lettres et des arts. Constantinople.

Viguer, P. F. (1790). Elemens De La Langue Turque. İstanbul.

Viotte, C. (1856). Grammaire turque courte et facile. Paris.

Youssouf, J. R. (1892). Grammaire Complete de la Langue Ottomane. İstanbul.

Youssouf, R. (1888). Dictionnaire turc-français en caractères latins . Constantinople 